\title{
Influence of Intimate Partners' Violence on Unintended Pregnancy in Bangladesh
}

\author{
Shahreen Raihana ${ }^{1, *}$, Rukhs ana Shahee ${ }^{2}$, Md. Shafiqur Rahman ${ }^{2}$ \\ ${ }^{1}$ Center for Child and Adolescent Health, International Centre for Diarrhoeal Diseases Research(icddr,b), Ban gladesh \\ ${ }^{2}$ Planning and Research Unit, Directorate General of Health Services (DGHS), Bangladesh
}

\begin{abstract}
Violence and unintended pregnancy are increasingly becoming essential public health issue in Bangladesh. The study aimed to examine the influence of vio lence on unintended pregnancy taking selected covariate into consideration. This study used nationally representative sample of the Bangladesh Health and Demographic Survey 2007 where data were obtained from 10,996 ever married women aged 10-49 years. Of them 4,925 women having their last birth in the last five years were selected for this study to analyze the violence victimization data. Chi-square and logistic regression analysis was done at $95 \%$ confidence interval. The mean age of the wo men was $25.9 \pm 6.3$ years. About 29.6 percent of the ever married wo men had suffered either physical or sexual violence from their partner at least once. Unintended pregnancy was 31.6 percent among the respondent women. Women exposed to at least one form of violence at least once, had 34.5 percent higher odds $(\mathrm{OR}=1.35 ; \mathrm{CI}=1.08$ to 1.67$)$ of having an unintended pregnancy. Intimate partner violence positively influenced unintended pregnancy. Unintended pregnancies due to intimate partner violence puts more burden on the existing population problem in Bangladesh. Hence, it is necessary to control intimate partner violence through favourable policy level decisions and strong social movements in order to address the problem.
\end{abstract}

Keywords Unintended Pregnancy, Violence, Intimate Partner, Bangladesh

\section{Introduction}

\subsection{Background}

Intimate partner violence has been defined as 'behavior within an intimate relationship that causes physical, sexual or psychological harm'[1-2]. Violence on wo men has always been an immensely analyzed and discussed issue across the world, but its association with unintended pregnancy has been explored to a limited extent in Bangladesh. The most common form of violence being the physical abuse inflicted upon the women by their intimate partners. This is increasingly becoming an essential public health issue due to the considerable effect on a wo man's physical, sexual, mental, and reproductive health[3]. Researches show how various birth outcomes, pregnancy coercion[4], induced abortion[5], unintended pregnancy[6-7], contraception use[6], fetal growth, childhood growth impairment and malnutrition [8-9] are at large associated with the forms of physical and sexual abuse that the women experience.

In South Asia, considerable prevalence of most forms of violence have been indicated over the last decade[10-12].

* Corresponding author:

shahreen_raihana@yahoo.com (Shahreen Raihana)

Published online at http://journal.sapub.org/ijpbs

Copyright (C) 2012 Scientific \& Academic Publishing. All Rights Reserved
Prevalence in Bangladesh has kept in line with most of the South Asian trend as shown in the World Health Organization (WHO) multi-country survey where it was found that 62.0 percent of the ever-married rural women in Bangladesh had a lifetime experience of violence[3]. Of the 208 million pregnancies worldwide in 2008, approximately 16 percent were reported as unintended[13]. Violence, including forced sexual interaction have been shown to be associated with unintended pregnancy in the World Report of Violence and Health[14]. But limited number of studies have been done in South Asia to see the association between partner violence and unintended pregnancy[6]. Although the exact figures could not be traced, but studies show that prevalence of unintended pregnancy among Bangladeshi rural women is higher than in Nigeria, and lower than in Philippines, Nepal, Guatemala, Ecuador and Vietnam[15]. A study emphasized on intimate partner violence (IPV) and unintended pregnancy in Bangladesh, the IPV perpetration data from the perspective of men was taken[7, 16].

The total fertility rate (TFR) in Bangladesh is 2.7 births per wo man and the total wanted fertility rate is 30.0 percent lower at 1.9 births per wo man. Thus, if all unintended births could be prevented, the TFR may be expected to drop considerably[17]. Using the Bangladesh Demographic and Health Survey (BDHS) data of 2007, this study used the IPV victimization data from women's perspective to understand its relationship with unintended pregnancy. This study also 
attempts to show that addressing violence inflicted on wo men may contribute to reduction in population growth in the country.

\subsection{Adjunct Thoughts and Researches}

A review article found that although there are good numbers of literature that explore the adverse physical and mental health consequences associated with IPV, only few have looked into its effect on women's fertility control to prevent unintended pregnancies. Unintended pregnancies were found to be associated with adverse outcomes for women and child health, especially in developing countries[18]. A case-control study found that women experiencing physical and emotional abuse were likely to report not using contraception in the past 12 months compared with non-abused women $(\mathrm{OR}=1.9 ; 95 \% \mathrm{CI}=1.0$ to 3.7)[19]. A study to investigate linkages between sexual violence and unintended pregnancy among Colombian female aged 13-24 years report that 13.0 percent female who have been pregnant in the past five years had experienced sexual violence during their lifetimes, with 6.0 percent reporting sexual violence perpetrated by partner and 8.0 percent by someone else. The study also found that unintended pregnancy was reported by 11.0 percent. Significantly higher level of unintended pregnancy and unmet need for contraception was also found among those exposed to violence[20].

Using the National Family Health Survey-2 in India conducted in 1998-99, considering a set of independent covariates such as age, place of residence, education, working status, religion, standard of living, type of family, number of surviving sons, use of contraceptive methods, pregnancies terminated, and physical mistreatment by the husband were evaluated using a multiple logistic regression model to come up with the finding that women who had been physically mistreated by their husbands were 47.0 percent more likely to experience unintended pregnancies (OR 1.47; 95\% CI 1.25-1.72)[21]. Several studies conducted in India indicate association of intimate partner violence and unintended pregnancy[22]. In the gender-stratified settings of India, relationship between a woman's experience of physical vio lence perpetrated by her husband and her ability to achieve her reproductive intentions was demonstrated[6].

Investigating unintended pregnancy and its association with physical abuse of wo men occurring around the time of pregnancy, independent of other factors, found that women who had mistimed or unintended pregnancies reported significantly higher levels of abuse at any time during the 12 months before conception or during pregnancy compared with those with intended pregnancies. The study used data from Pregnancy Risk Assessment Monitoring System of 1996-1997. Prenatal care can provide an important point of contact where women can be screened for violence and referred to services that can assist them was recommended by the study[23]. Apart from the scenario in developing countries, a cross-sectional survey among females aged
16-29 years seeking care in five family planning clinics in Northern California documented that 53.0 percent reported physical or sexual partner violence, 19.0 percent reported experiencing pregnancy coercion, and 15.0 percent reported partner interference with contraception[4]. Regardless of other characteristics, a study among American women in selected states showed that unintended or mistimed pregnancies were associated with higher prevalence of physical violence than did women with intended pregnancies [24].

In Uganda, studies show women in abusive relationships may have unintended or unplanned pregnancy which lead them to consider pregnancy termination as an option. Do mestic vio lence increases the possibility of pregnancy by affecting pre-conception and post-conception need for pregnancy [5]. A limited scale study in Ch ina, which is varied in its socio-demographic-politico characteristics, highlighted that sexual, physical and psychological violence may contribute, both directly and indirectly, to unintended pregnancy and abortion-related morbidity and mortality leading to increased number of wo men seeking abortion[25].

\subsection{Problem State ment}

Unintended pregnancy and a reduction in birth interval may occur as a result of various forms of violence inflicted upon women by their intimate partners. Existence of such a problem is not unlikely in Bangladesh[12]. Scientists have tried to relate violence by intimate partner with different social facets, but the influence of violence by male partners on unintended pregnancy in female partner has not been delved elaborately. In this study, a national sample of Bangladesh has been used to elaborately examine this relationship between IPV and unintended pregnancy.

\subsection{Rationale}

This study analyzes a national sample of Bangladesh to ascertain the relation between intimate male partner violence with unintended pregnancy to add to the body of knowledge, and assist policy implication for the betterment of welfare services for women. Consequently, propose areas where intervention programs may be incorporated to minimize population growth pattern.

\subsection{Hypotheses}

Any form of intimate male partners' violence is positively associated with unintended pregnancy in Bangladesh.

\subsection{Objective}

To find the association of violence with unintended pregnancy

\subsection{Operational Definitions}

\subsubsection{Intimate Male Partner}

It is considered to be a male who is in an intimate relationship (physical and/or sexual) with a female within or outside of marriage. 


\subsubsection{Intimate Female Partner}

It is considered to be a female who is in an intimate relationship (physical and/or sexual) with a male within or outside of marriage.

\subsubsection{Violence}

For this study, violence refers to exertion of physical force so as to injure or abuse.

\subsubsection{Unintended Pregnancy}

This refers to a condition when a female within the intimate relationship with a male expressed that the last pregnancy that she experienced was unintended or unplanned.

\subsubsection{Hous ehold Wealth Index}

To create the wealth index, each household asset was assigned a weight or factor score which were standardized and divided into quintiles from one (lowest) to five (highest). For this study, the lower two quintiles have been grouped as 'poor', the higher two quintiles have been grouped as 'rich', and the middle quintile has been retained as 'middle'.

\subsubsection{Currently Married}

Both the partners are alive and married at the time of data collection.

\subsubsection{Women's Nutritional Status}

A cut-off point in the Body Mass Index (BMI) of 18.5 $\mathrm{kg} / \mathrm{m}^{2}$ is used to define under-nutrition. A BMI of $25 \mathrm{~kg} / \mathrm{m}^{2}$ or above indicates overweight and $30 \mathrm{~kg} / \mathrm{m}^{2}$ or above indicates obesity.

\subsection{Scope of Study}

It was assumed that in the backdrop of male dominated Bangladesh society, the study would give a snapshot of the existing situation in Bangladesh where violence and unintended pregnancy are reported but not in relation to each other. Because of time and resource constraint this study was kept limited to few variables with the potential to relate violence with unintended pregnancy. Further exhaustive study considering a wider array of social facets would give a complete picture. Using demographic and health survey data has the limitation that a temporal relationship cannot be brought into the analysis to get a clearer picture. Retrospective data of women's pregnancy intention could not be seen, which may have lead to recall bias and misreporting. Moreover, the data used is from a survey of 2007, current empirical data would have given more complete and updated information. In this study, only male perpetrated violence was considered, female perpetrated violence was not delved into. A combination of the two perspectives could have shown a more intricate web of socio-psychological as sociation.

\section{Methods}

\subsection{Study Population and Study Area}

This study has been attempted by using a nationally representative cross-sectional sample of the Bangladesh Health and Demographic Survey 2007. The Domestic Violence Module is included among the various parameters obtained from 10,996 ever married women aged 10 to 49 years. Those who were not married at the time of data collection and those who did not give proper information about the violence inflicted upon them were considered as missing. Of the 10,996 women, 4,925 wo men having their last birth in the last five years and having data for wanting the most recent pregnancy were selected for this study.

\subsection{Me as urement of Violence}

'Violence' is the predictor variable considered for the study. A woman was considered to have undergone physical violence by her intimate partner if she replied affirmatively to any one of the following queries - if her partner pushed, shook, or threw something at her; slapped her; twisted arm or pulled her hair; punched her with his fist or with something that could hurt her; kicked, dragged, or beat her; tried to choke or burn her on purpose; and/or threatened or attacked her with a knife, gun, or any other weapon[17, 26-27]. If all of these queries were negatively replied then she was reported as 'no violence'. Sexual abuse was similarly determined by affirmative reply when asked if her partner ever physically forced her to have sexual intercourse with him even when she did not want to do so[17, 26].

\subsection{Me as urement of Unintended Pregnancy}

'Unintended pregnancy' was considered as the outcome variable. Intention of the last pregnancy in the last five years was categorized in the BDHS as having wanted the pregnancy 'then', 'later' or 'not at all'. In this study, the latter two categories were considered as 'unintended pregnancy' while the former was considered as 'intended pregnancy'.

\subsection{Analysis}

The outcome variable of pregnancy intention was analyzed by categorizing the women into few more covariates which are known to have influence on both the predictor and outcome variables or has a proven evidence of such influence. Demographic variables like women's age, educational status, urban-rural residence, number of living children, wealth index, employment of respondent and partner, religion, partner's education was considered for the bivariate analysis, and later incorporated into the multivariate model depending on the significance of association and evidence from other studies. The wealth index was constructed from data on household assets and dwelling characteristics. 
In the bivariate analysis, influence of the different socio-economic characteristics, nutritional status, and reproductive health status of the women on unintended pregnancy was looked into. Individual chi-square tests were performed taking $0.05(\mathrm{CI}=95 \%)$ as the level of significance to see the association between the covariates with partner violence and unintended pregnancy. Reproductive health variables like use of contraception, or discussion on family planning with partner was considered for incorporation into the logistic regression model to determine the gross and the net Odds Ratio $(\mathrm{CI}=95 \%)$. The $-2 \log$ likelihood of this model was calculated to be 5681.19 which is sufficiently high to prove the fitness of the model. All analyses were performed using the Statistical Package for the Social Sciences Software (SPSS) version 11.5 (SPSS Inc, Chicago, IL).

\subsection{Ethical Consideration}

The permission to share the BDHS 2007 data was taken by an academician in Bangladesh who shared the data with the researchers on the understanding that it will be used for the purpose of research only and that the source will be duly acknowledged. The BDHS document shows that informed consent was obtained from survey respondents with the assurance of confidentiality and anonymity. Plagiaris $m$ was avoided in this write-up. The data was used in different combination without any manipulation of figures. No intervention was done on human subjects as the study is content analysis. It is understood that privacy was strictly maintained during data collection for the Domestic Violence Module used for the Demographic and Health Survey that used the modified Conflict Tactics Scale (CTS) by forty-two staffs trained for the purpose[17].

\section{Results}

\subsection{Frequency of Unintended Pregnancy and Partner Violence}

It was found that 24.2 percent of the ever married women with their last birth in last five years had suffered physical violence while 12.6 percent suffered sexual violence from their male partner at least once as shown in Table 1 . The prevalence of either physical or sexual violence at least once is 29.6 percent, though the summation of percentage of the two types of violence is different. Slapping was found to be the most common form of physical violence which accounted for 22.4 percent. The sample data also indicated that 31.6 percent of the births in the last five years were unintended.

\subsection{Char acteristics of the Women}

Majority 64.5 percent of the wo men were fro $m$ rural areas in Bangladesh as shown in Table 2. About 21.3 percent of them were from Dhaka, followed by 19.9 percent from Chittagong and 12.6 percent from Khulna division. About
97.7 percent were currently married women. Highest 35.4 percent of women were found to have secondary level of education. About 75.2 percent of the women were unemployed. Measurement of household wealth index shows that highest 42.5 percent of women were rich, and highest 36.9 percent of wo men had 3 or mo re living children. Use of contraceptives was found to be 84.3 percent. The mean age of the wo men at the time of the survey was $25.9 \pm 6.3$ years.

Table 1. Distribution of Unintended Pregnancy and Partner Violence

\begin{tabular}{|c|c|}
\hline $\begin{array}{c}\text { Prevalence of unintended pregnancy } \\
(\mathrm{n}=4925)\end{array}$ & $1557(31.6)$ \\
\hline $\begin{array}{c}\text { Prevalence of physical violence on } \\
\text { women* }(\mathrm{N}=2065)\end{array}$ & $500(24.2)$ \\
\hline Pushed & $310(14.9)$ \\
\hline Slapped & $465(22.4)$ \\
\hline Punched & $187(9.0)$ \\
\hline Kicked or dragged & $153(7.3)$ \\
\hline Choked or burnt & $71(3.4)$ \\
\hline Threatened with knife/gun/other & $10(0.5)$ \\
\hline Twisted arm or pulled hair & $157(7.5)$ \\
\hline $\begin{array}{c}\text { Prevalence of sexual violence on women } \\
\text { (n=2091) }\end{array}$ & $264(12.6)$ \\
\hline $\begin{array}{c}\text { Prevalence of either physical or sexual } \\
\text { violence (at least once) }(\mathrm{n}=2063)\end{array}$ & $610(29.6)$ \\
\hline
\end{tabular}

* Multiple response

Table 2. Background Characteristics of the Women

\begin{tabular}{|c|c|}
\hline Background characteristics & n (\%) \\
\hline \multicolumn{2}{|l|}{ Place of residence of women $(n=4925)$} \\
\hline Rural & $3177(64.5)$ \\
\hline Urban & $1748(35.5)$ \\
\hline \multicolumn{2}{|c|}{ Division of residence of women $(n=4925)$} \\
\hline Barisal & $658(13.4)$ \\
\hline Chittagong & $980(19.9)$ \\
\hline Dhaka & $1050(21.3)$ \\
\hline Khulna & $623(12.6)$ \\
\hline Rajshahi & $829(16.8)$ \\
\hline Sylhet & $785(15.9)$ \\
\hline Currently married women $(n=4925)$ & $4810(97.7)$ \\
\hline \multicolumn{2}{|c|}{ Women's education $(n=4922)$} \\
\hline No education & $1267(25.7)$ \\
\hline Primary & $1507(30.6)$ \\
\hline Secondary & $1742(35.4)$ \\
\hline Higher & $406(8.2)$ \\
\hline \multicolumn{2}{|c|}{ Women's employment $(n=4923)$} \\
\hline Unemployed & $3703(75.2)$ \\
\hline Employed & $1220(24.8)$ \\
\hline \multicolumn{2}{|c|}{ Household wealth index $(\mathrm{n}=4925)$} \\
\hline Poor & $1924(39.1)$ \\
\hline Middle & $910(18.5)$ \\
\hline Rich & $2091(42.5)$ \\
\hline \multicolumn{2}{|c|}{ Number of living children of women $(n=4925)$} \\
\hline$\leq 1$ & $1697(34.5)$ \\
\hline 2 & $1411(28.6)$ \\
\hline $3+$ & $1817(36.9)$ \\
\hline \multicolumn{2}{|c|}{ Use of contraceptive by women $(n=4925)$} \\
\hline No & $772(15.7)$ \\
\hline Yes & $4153(84.3)$ \\
\hline Mean age of women $(n=4925)$ & $\begin{array}{l}25.9 \pm 6.3 \\
\text { years }\end{array}$ \\
\hline
\end{tabular}




\subsection{Women's Characteristics and Unintended Pregnancy}

Table 3. Frequency of Unintended Pregnancy in Last Five Years by Characteristics of Women

\begin{tabular}{|c|c|c|}
\hline Variables & $\begin{array}{c}\text { Unintended } \\
\text { pregnancy in last five } \\
\text { years, } \%(n=4925)\end{array}$ & $\mathrm{p}$-value \\
\hline Religion & & $<.01$ \\
\hline Muslim & 32.3 & \\
\hline Non-Muslim & 24.5 & \\
\hline Women's education & & $<.001$ \\
\hline No education & 35.8 & \\
\hline Primary & 33.5 & \\
\hline Secondary & 27.8 & \\
\hline Higher & 27.8 & \\
\hline Women's employment & & .052 \\
\hline Unemployed & 30.9 & \\
\hline Employed & 33.9 & \\
\hline Household wealth index & & .094 \\
\hline Poor & 32.9 & \\
\hline Middle & 32.7 & \\
\hline Rich & 29.9 & \\
\hline Division of residence & & .131 \\
\hline Barisal & 33.0 & \\
\hline Chittagong & 33.3 & \\
\hline Dhaka & 32.9 & \\
\hline Khulna & 27.8 & \\
\hline Rajshahi & 29.6 & \\
\hline Sylhet & 32.0 & \\
\hline Place of residence & & .192 \\
\hline Urban & 32.8 & \\
\hline Rural & 31.0 & \\
\hline Partners education & & $<.01$ \\
\hline No education & 34.5 & \\
\hline Primary & 32.5 & \\
\hline Secondary & 29.6 & \\
\hline Higher & 26.4 & \\
\hline Women's nutritional stat us & & .148 \\
\hline Underweight & 33.0 & \\
\hline Normal & 31.4 & \\
\hline Overweight & 28.7 & \\
\hline Obese & 23.8 & \\
\hline Exposure to media & & $<.05$ \\
\hline Unexposed & 33.8 & \\
\hline Exposed & 30.4 & \\
\hline Partner's employment & & $<.05$ \\
\hline Agricultural & 28.3 & \\
\hline Semi-skilled worker & 33.9 & \\
\hline Skilled worker & 30.3 & \\
\hline Businessmen & 31.7 & \\
\hline Unemployed & 29.2 & \\
\hline Number of living children & & $<.001$ \\
\hline$\leq 1$ & 16.6 & \\
\hline 2 & 29.7 & \\
\hline $3+$ & 47.2 & \\
\hline Use of contraceptive & & $<.001$ \\
\hline No & 22.9 & \\
\hline Yes & 33.2 & \\
\hline $\begin{array}{l}\text { Physical or sexual violence } \\
\text { (at least once)* }\end{array}$ & 35.1 & $<.05$ \\
\hline
\end{tabular}

More unintended pregnancies were found among Muslims which accounts for 32.3 percent as shown in Table
3. Unintended pregnancy among women without any form of formal education was found to be 35.8 percent. The occurrence of unintended pregnancy was seen to decrease significantly with increased level of education of the women. Women's employment showed an unexpected relation with intent of pregnancy. About 33.9 percent of employed women had unintended pregnancy, while 30.9 percent of those unemployed had unintended pregnancy. The association was statistically not significant.

Women from rich class reported 29.9 percent of their pregnancies to be unintended. Middle and poor class reported respectively 32.7 percent and 32.9 percent of their pregnancies to be unintended. This difference is insignificant. Unintended pregnancy is high in Chittagong division at 33.3 percent, and lowest in Khulna at 27.8 percent. This distribution of unintended pregnancy across the divisions was insignificant. Place of residence was not found to have significantly in fluenced either the pattern of violence or the intention of pregnancy, although unintended pregnancy was higher among the urban residents.

Women with uneducated partners showed a highest of 34.5 percent unintended pregnancies, while it was lowest at 26.4 percent for partners who attended higher education. This pattern was significant. A lthough result showed that underweight respondents had a higher percentage of unintended pregnancy than the normal weight and overweight ones, but the differences were statistically not significant. Exposure to media showed significant association with unintended pregnancy. Among those who were exposed to media, 30.4 percent reported to have unintended pregnancy, while 33.8 percent of the unexposed ones reported unintended pregnancy. About 33.9 percent wo men with semi-skilled worker as partner reported to have had an unintended pregnancy. The least unintended pregnancy of 28.3 percent was noted among women with partners working in agriculture. This association was significant. Number of children a woman has was found to be significantly associated with the pregnancy unintendedness. Among women who already have one child, 16.6 percent reported unintended pregnancy. At the same time, 29.7 percent of those with 2 children and 47.2 percent of those with 3 or more children reported having unintended pregnancy. Those who used more contraceptive do not expect to become pregnant, and so any failure in contraception is considered as unintended pregnancy. On the whole, 35.1 percent women who were either physically or sexually abused by their partner, reported unintended pregnancy. This association was found significant.

\subsection{Violence and Unintended Pregnancy}

The gross effects of any form of violence by intimate partner, either physical or sexual, on the intention of last pregnancy in the previous five years significantly increase when the other socioeconomic characteristics and reproductive health characteristics were incorporated into the model in Table 4. Women who were exposed to at least 
one form of violence at least once, have 27.3 percent higher odds ( $\mathrm{OR}=1.27$; $\mathrm{CI}=1.04$ to 1.56$)$ of having an unintended pregnancy than women who did not face any form of violence. Similarly, incorporation of other covariates religion, wo men's education, wo men's employment, wealth index, residence, partner's education, exposure to media, partner's employ ment, nu mber of living children, and use of contraceptive - showed that women who faced violence had 34.5 percent higher odds $(\mathrm{OR}=1.35 ; \mathrm{CI}=1.08$ to 1.67$)$ of having an unintended childbirth in preceding five years. So the net effect increased when adjusted for confounders and covariates.

Table 4. Multi-variate Association between Intimate Partner's Violence and Unintended Pregnancy in Unadjusted and Adjusted Models

\begin{tabular}{|c|c|c|c|c|}
\hline \multirow{3}{*}{ Variable } & \multicolumn{4}{|c|}{ Unintended pregnancy in last five years } \\
\hline & \multicolumn{2}{|c|}{ Unadjusted model } & \multicolumn{2}{|c|}{ Adjusted model } \\
\hline & $\mathrm{OR}(\mathrm{CI})$ & $\mathrm{p}$ value & $\mathrm{OR}(\mathrm{CI})$ & $\mathrm{p}$ value \\
\hline $\begin{array}{l}\text { Violence by } \\
\text { intimate partner } \\
\text { of any form at } \\
\text { least once }\end{array}$ & $\begin{array}{c}1.27 \\
(1.04,1.56)\end{array}$ & .018 & $\begin{array}{c}1.34 \\
(1.08,1.67)\end{array}$ & .007 \\
\hline \multicolumn{5}{|c|}{ Religion } \\
\hline Muslim & $\begin{array}{c}1.47 \\
(1.18,1.84)\end{array}$ & .001 & $\begin{array}{c}1.30 \\
(1.03,1.64)\end{array}$ & .026 \\
\hline Non-Muslim & 1.00 & - & 1.00 & - \\
\hline \multicolumn{5}{|c|}{ Women's education } \\
\hline No education & 1.00 & - & 1.00 & - \\
\hline Primary & $\begin{array}{c}.90 \\
(.77,1.05) \\
\end{array}$ & .201 & $\begin{array}{c}1.19 \\
(1.00,1.42)\end{array}$ & .048 \\
\hline Secondary & $\begin{array}{c}.69 \\
(.59, .80) \\
\end{array}$ & .000 & $\begin{array}{c}1.35 \\
(1.10,1.67) \\
\end{array}$ & .005 \\
\hline Higher & $\begin{array}{c}.69 \\
(.54, .88) \\
\end{array}$ & .003 & $\begin{array}{c}1.60 \\
(1.12,2.29) \\
\end{array}$ & .010 \\
\hline \multicolumn{5}{|c|}{ Women's employment } \\
\hline Unemployed & 1.00 & - & 1.00 & - \\
\hline Employed & $\begin{array}{c}1.15 \\
(.99,1.32) \\
\end{array}$ & .052 & $\begin{array}{c}1.04 \\
(.90,1.21) \\
\end{array}$ & .574 \\
\hline \multicolumn{5}{|c|}{ Wealth index } \\
\hline Poor & $\begin{array}{c}1.007 \\
(.85,1.19)\end{array}$ & .935 & $\begin{array}{c}.91 \\
(.76,1.10)\end{array}$ & .338 \\
\hline Middle & 1.00 & - & 1.00 & - \\
\hline Rich & $\begin{array}{c}.88 \\
(.74,1.04) \\
\end{array}$ & .126 & $\begin{array}{c}.86 \\
(.71,1.05) \\
\end{array}$ & .131 \\
\hline \multicolumn{5}{|c|}{ Place of residence } \\
\hline Rural & 1.00 & - & 1.00 & - \\
\hline Urban & $\begin{array}{c}1.09 \\
(.96,1.23) \\
\end{array}$ & .192 & $\begin{array}{c}1.12 \\
(.96,1.30) \\
\end{array}$ & .144 \\
\hline \multicolumn{5}{|c|}{ Partner's education } \\
\hline No education & 1.00 & - & 1.00 & - \\
\hline Primary & $\begin{array}{c}.91 \\
(.78,1.06)\end{array}$ & .251 & $\begin{array}{c}1.00 \\
(.85,1.19)\end{array}$ & .966 \\
\hline Secondary & $\begin{array}{c}.80 \\
(.68, .93) \\
\end{array}$ & .005 & $\begin{array}{c}.90 \\
(.74,1.09) \\
\end{array}$ & .290 \\
\hline Higher & $\begin{array}{c}.68 \\
(.55, .83) \\
\end{array}$ & .000 & $\begin{array}{c}.70 \\
(.51, .95) \\
\end{array}$ & .022 \\
\hline \multicolumn{5}{|c|}{ Exposure to media } \\
\hline Unexposed & 1.00 & - & 1.00 & - \\
\hline Exposed & $\begin{array}{c}.86 \\
(.76, .97) \\
\end{array}$ & .015 & $\begin{array}{c}1.01 \\
(.86,1.18) \\
\end{array}$ & .893 \\
\hline \multicolumn{5}{|c|}{ Partner's employment } \\
\hline Unemployed & 1.00 & - & 1.00 & - \\
\hline
\end{tabular}

\begin{tabular}{|c|c|c|c|c|}
\hline Agricultural & $\begin{array}{c}1.07 \\
(.73,1.56)\end{array}$ & .725 & $\begin{array}{c}.84 \\
(.56,1.26)\end{array}$ & .409 \\
\hline $\begin{array}{c}\text { Semi-skilled } \\
\text { worker }\end{array}$ & $\begin{array}{c}1.39 \\
(.97,2.00)\end{array}$ & .075 & $\begin{array}{c}1.22 \\
(.83,1.80)\end{array}$ & .308 \\
\hline Skilled worker & $\begin{array}{c}1.18 \\
(.75,1.86)\end{array}$ & .481 & $\begin{array}{c}1.23 \\
(.73,2.08)\end{array}$ & .434 \\
\hline Businessmen & $\begin{array}{c}1.26 \\
(.86,1.83)\end{array}$ & .232 & $\begin{array}{c}1.08 \\
(.73,1.61)\end{array}$ & .703 \\
\hline \multicolumn{5}{|c|}{ Number of living children to women } \\
\hline$\leq 1$ & $\begin{array}{c}.47 \\
(.40, .56)\end{array}$ & .000 & $\begin{array}{c}.48 \\
(.40, .57)\end{array}$ & .000 \\
\hline 2 & 1.00 & - & 1.00 & - \\
\hline $3+$ & $\begin{array}{c}2.11 \\
(1.82,2.45)\end{array}$ & .000 & $\begin{array}{c}2.31 \\
(1.98,2.70)\end{array}$ & .000 \\
\hline \multicolumn{6}{|c|}{ Use of contraception } \\
\hline Never Used & 1.00 & - & 1.00 & - \\
\hline Ever Used & $\begin{array}{c}1.67 \\
(1.40,2.00)\end{array}$ & .000 & $\begin{array}{c}1.43 \\
(1.17,1.73)\end{array}$ & .000 \\
\hline
\end{tabular}

\section{Discussion, Conclusions and Implication}

\subsection{Discus sion}

The results from the study show significant association between IPV and unintended pregnancy. Women who have the history of having faced any form of physical or sexual violence have reported unintended pregnancy more and this percentage was higher in the adjusted model than in the unadjusted one. It is likely that there was underreporting of unintended pregnancy. The violence is probably due to male domination in the society where the women are considered subservient as is in many other countries[28]. Any voice raised by women against violence is possibly subdued by further violence, and result in familial disharmony. This in turn deters women from reporting violence by partner. Majority of the women studied were from rural areas in Bangladesh. It is noted that women's education is probably gaining mo mentum in Bangladesh, but they prefer not to take up employ ment outside homestead. Hous ehold wealth index indicate that the economic solvency was probably ascribed rather than earned by self. The number of living children indicate that the 'replacement level fertility' concept promoted in Bangladesh is probably not gaining ground among the women in spite of the use of contraceptives being high[29].

Unintended pregnancies were seen to be higher among Muslims whose religious and cultural norms probably prompt conservative thinking which deters the use of contraceptives[15]. Though the unadjusted model shows that with higher education of women, unintended pregnancy decreases, but the adjusted model shows an insignificant positive association as is observed in a study in Columbia using their Demographic and Health Survey (DHS) data[26]. The higher educated women tend to report any form of violence and unintended pregnancy more frequently in comparison to the uneducated or less educated women[16]. The study shows that women's employment has no association with unintended pregnancy. Studies in United 
States of America (USA) have found that employed wo men have higher number of unintended pregnancies[30]. It may be that for employed women in USA carrier becomes first priority and so are reluctant to allow pregnancy to interrupt their career. On the contrary, Bangladeshi women are most likely less career oriented and take pregnancy more in their stride.

Accessing family planning services is possibly influenced by the higher buying capacity of services by rich, which is similar to results obtained from DHS data of Moldova[7]. Specific influence of administrative division on unintended pregnancy and any form of violence could not be shown since other social dynamics are possibly involved in such situation. Evidence from Urban Health Survey 2006 shows that urban population in Bangladesh have a high TFR in slum areas which surpass that in rural areas[31]. The same is reflected in this study. Unintended pregnancy is considered as one contributing factor for raised TFR. Educated partners are more likely to refrain from violence and use contraception leading to less unintended pregnancy. The popular adage 'education is the best contraceptive' probably stands true even today[32].

Pregnancy in underweight wo men make them physically more weak and they assume pregnancy to be a burden on their health and so report the pregnancy as unintended. The relationship between under-nutrition and unintended pregnancy is insignificant, but for inferential knowledge further studies are needed. Significant negative influence of exposure to media is noted in the unadjusted model, but influence becomes negligible in the adjusted model. It is like ly that other forms of co mmun ication also come into play to raise awareness regarding unintended pregnancy. In a study in South Africa, the women whose partners were employed probably view a pregnancy to be unintended with regard to their limited resources [33]. Bangladesh is a limited resource country, where women of the employed partners have higher unintended pregnancy since they realize that they might not be able to rear their children as social capital if the number of children is more. In an Ethiopian study, wo men with large number of living child ren were found to report their previous birth as unintended[34]. In Bangladesh too, wo men who are alert to the resource constraints that may follow the birth probably term the pregnancy as unintended. The association between unintended pregnancy and contraceptive use reflects the possibility of adopting contraception after previous unintended pregnancy has occurred so as to avoid further unintended births. Other studies show that the threats of violence immensely influence not using contraception and thus lead to higher number of unintended pregnancy $[6,15]$.

\subsection{Conclusions}

The study revealed significant positive association between intimate partner violence and unintended pregnancy proving the hypothesis to stand. Bearing in mind the religio-socio-cultural backdrop in Bangladesh, it is likely that there is underreporting of violence and unintended pregnancy by women. Occurrence of violence is less tolerated by higher educated women, which leads to more reporting. People with higher buying capacity have greater access to family planning services and less unintended pregnancy. The great diversity and complexity of the social dynamics in Bangladesh have not been fully captured in the analysis of the national sample. Further empirical study is expected to give more conclusive results. It is recommended that both men and women receive formal education, and be exposed to awareness raising attempts regarding violence and pregnancy intention.

\subsection{Implications}

In a country like Bangladesh where population growth is high, unintended pregnancies due to intimate partner violence puts more burden on the existing population problem. Therefore, it is crucial to prevent intimate partner violence to control this high level of unintended pregnancies. Scientists and other concerned need to work more to control population taking into account unintended pregnancy and violence on women. Hence, it is necessary to control intimate partner violence through favorable policy level decisions and strong social movements in order to address the problem. Enforcement of social control mechanisms may add to efforts. Measures need to be put in place such that wo men feel free to report any form of violence.

\section{ACKNOWLEDGMENTS}

Whole-hearted gratitude to Wasimul Bari of the University of Dhaka, Bangladesh for sharing the BDHS 2007 data. Thanks to academicians Omar Ezaz Rah man and Kuntal Kumar Saha of Bangladesh who extended their guidance during the research.

\section{REFERENCES}

[1] Krug, E.G., World report on violence and health. 2002, Geneva: World Health Organization. xxii, 346 p.

[2] Finney, A., Alcohol and intimate partner violence : key findings from the research. 2004, London: Home Office. 1 folded sheet $(6 \mathrm{p}$.).

[3] Garcia-Moreno, C., et al., Prevalence of intimate partner violence: findings from the WHO multi-country study on women's health and domestic violence. Lancet, 2006. 368(9543): p. 1260-9.

[4] Miller, E., et al., Pregnancy coercion, intimate partner violence and unintended pregnancy. Contraception, 2010. 81(4): p. 316-22.

[5] Kaye, D.K., et al., Domestic violence as risk factor for unwanted pregnancy and induced abortion in Mulago Hospital, Kampala, Uganda. Trop Med Int Health, 2006. 11(1): p. 90-101. 
[6] Stephenson, R., et al., Domestic violence, contraceptive use, and unwanted pregnancy in rural India. Stud Fam Plann, 2008. 39(3): p. 177-86.

[7] Ismayilova, L., Intimate Partner Violence and Unintended Pregnancy in Azerbaijan, Moldova, and Ukraine. DHS Working Papers No. 79., 2010. Calverton, Maryland, USA: ICF Macro.

[8] Asling-Monemi, K., R.T. Naved, and L.A. Persson, Violence against women and the risk of fetal and early childhood growth impairment: a cohort study in rural Bangladesh. Arch Dis Child, 2009. 94(10): p. 775-9.

[9] Rico, E., et al., Associations between maternal experiences of intimate partner violence and child nutrition and mortality: findings from Demographic and Health Surveys in Egypt, Honduras, Kenya, Malawi and Rwanda. J Epidemiol Community Health, 2011. 65(4): p. 360-7.

[10] Babu, B.V. and S.K. Kar, Domestic violence against women in eastern India: a population-based study on prevalence and related issues. BMC Public Health, 2009. 9: p. 129.

[11] Jeyaseelan, L., et al., Physical spousal violence against women in India: some risk factors. J Biosoc Sci, 2007. 39(5): p. 657-70.

[12] Silv erman, J.G., et al., Violence against wives, sexual risk and sexually transmitted infection among Bangladeshi men. Sex Transm Infect, 2007. 83(3): p. 211-5.

[13] Facts on induced abortion worldwide: Worldwide incidences and trends. Alan Guttmacher Institute. 2011. http://www.guttmacher.org/pubs/fb_IAW.html\#r15a.

[14] Krug, E.G., et al., The world report on violence and health. Lancet, 2002. 360(9339): p. 1083-8.

[15] Kamal, M. and A. Islam, Prevalence and socioeconomic correlates of unintented pregnancy among women in rural Bangladesh. Salud Publica Mex, 2011. 53(2): p. 108-15.

[16] Hindin, M.J., S. Kishor, and D.L. Ansara, Intimate partner violence among couples in 10 DHS countries : predictors and health outcomes. DHS analytical studies. 2008, Calverton, MD.: Macro International Inc. xv, $78 \mathrm{p}$.

[17] National Institute of Population Research and Training (Bangladesh), Mitra and Associates (Firm), and Macro International., Bangladesh demographic and health survey, 2007. 2009, Dhaka, 346 p.

[18] Pallitto, C.C., J.C. Campbell, and P. O'Campo, Is intimate partner violence associated with unintended pregnancy? A review of the literature. Trauma Violence Abuse, 2005. 6(3): p. 217-35.

[19] Williams, C.M., U. Larsen, and L.A. McCloskey, Intimate partner violence and women's contraceptive use. Violence Against Women, 2008. 14(12): p. 1382-96.

[20] Gomez, A.M., Sexual Violence as a Predictor of Unintended Pregnancy, Contraceptive Use, and Unmet Need Among Female Youth in Colombia. J Womens Health (Larchmt), 2011.
[21] Begum, S., et al., Association between domestic violence and unintended pregnancies in India: findings from the National Family Health Survey-2 data. Natl Med J India, 2010. 23(4): p. 198-200.

[22] Silverman, J.G., et al., Intimate partner violence and unwanted pregnancy, miscarriage, induced abortion, and stillbirth among a national sample of Bangladeshi women. BJOG, 2007. 114(10):p. 1246-52.

[23] Gazmararian, J.A., et al., Violence and reproductive health: current knowledge and future research directions. Matern Child Health J, 2000. 4(2): p. 79-84.

[24] Gazmararian, J.A., et al., The relationship between pregnancy intendedness and physical violence in mothers of newborns. The PRAMS Working Group. Obstet Gynecol, 1995. 85(6): p. 1031-8.

[25] Wu, J., S. Guo, and C. Qu, Domestic violence against women seeking induced abortion in China. Contraception, 2005. 72(2): p. 117-21.

[26] Pallitto, C.C. and P. O'Campo, The relationship between intimate partner violence and unintended pregnancy: analysis of a national sample from Colombia. Int Fam Plan Perspect, 2004. 30(4): p. 165-73.

[27] Silverman, J.G., et al., Maternal experiences of intimate partner violence and child morbidity in Bangladesh: evidence from a national Bangladeshi sample. Arch Pediatr Adolesc Med, 2009. 163(8): p. 700-5.

[28] Klein, D., Violence against women: Some considerations regarding its causes and its elimination. Crime \& Delinquency, 1981. 27(1): p. 64-80.

[29] Rahman, M., J. DaVanzo, and A. Razzaque, When will Bangladesh reach replacement-level fertility? The role of education and family planning services. United States Agency for International Development. 2003.

[30] Santelli, J.S., et al., An exploration of the dimensions of pregnancy intentions among women choosing to terminate pregnancy or to initiate prenatal care in New Orleans, Louisiana. Am J Public Health, 2006. 96(11): p. 2009-15.

[31] Angeles, G., National Institute of Population Research and Training (Bangladesh), and MEASURE Evaluation Project., 2006 Bangladesh urban health survey. 2008, Dhaka: National Institute of Population Research and Training. 1 v. (various pagings).

[32] Carr, D., et al., Is Education the Best Contraceptive. 2000: Population Reference Bureau, MEASURE Communication.

[33] Bafana, T., Factors influencing contraceptive use and Unplanned pregnancy in a South African Population, in Faculty of Health Sciences, University of the Witwatersrand[unpublished]. 2010.

[34] Dibaba, Y., Child Spacing and Fertility Planning Behavior among Women in Mana District, Jimma Zone, South West Ethiopia. Ethiopian Journal of Health Sciences, 2011. 20(2). 